\title{
El imaginario literario argentino en los escritores de la diáspora
}

Ariela Borgogno •

Universidad Autónoma de Entre Ríos

"París... es como nacer de nuevo para un argentino", escribe Manuel Mujica

Lainez en Invitados en el Paraíso. Estas palabras son recuperadas oportunamente por Gasquet como epígrafe de "El puente cultural entre Buenos Aires y París", quinto capítulo de su libro y momento de enlace entre las dos grandes partes que lo constituyen. ¿Por qué la relevancia de estas palabras? Porque Francia fue el referente por excelencia de la élite intelectual que diera origen a la nación y a la literatura argentina.

La relación de la cultura argentina con la europea fue, hace casi dos siglos, una de las problemáticas medulares que influyeron en la fundación de la literatura nacional. Luego de la emancipación del dominio español, junto al proyecto de construcción de una nación, nacía también el de la construcción de una literatura propia. Mariano Moreno, siempre inspirado por las ideas del Iluminismo, sostenía en aquel momento la inviabilidad de un proyecto político disociado de un proyecto cultural. Los intelectuales argentinos de la época tenían una formación predominantemente europea por lo tanto, y más allá de los aportes autóctonos, la configuración de una literatura nacional sólo podía abrirse camino a partir de la literatura del viejo continente. Fue Francia el modelo cultural a seguir y desde entonces, la ascendencia francesa en el campo cultural argentino, y en especial en la literatura, se prolonga con mayor o menor fuerza hasta nuestros días.

Esta última idea es la que recorre el libro que hoy reseñamos y el que, en palabras del autor, "trata de establecer la existencia de una comunidad de espíritu entre los escritores argentinos contemporáneos que residen en París, (...) comunidad que se sustenta en la historia literaria argentina y en su imaginario social.” (Gasquet, 2007: 7).

En el marco de la sociología de la literatura, es decir, tomando el texto literario como modo de conocimiento de la realidad social de un momento histórico determinado, Gasquet se propone analizar el imaginario literario argentino en los escritores expatriados de la actualidad. A partir de la idea de "la ficción, como clave interpretativa de la realidad", divide su trabajo en dos grandes secciones.

\footnotetext{
- Profesora en Letras, egresada de la UNL. Auxiliar Docente de la cátedra de Literatura Francesa e Italiana del Profesorado de Lengua y Literatura de la Facultad de Humanidades, Artes y Ciencias Sociales de la UADER (Universidad Autónoma de Entre Ríos). En el mismo Profesorado dicta la cátedra de Literatura Inglesa. Becaria de Centro di Studi Leopardiani, Recanati, Italia, en 1998. Miembro Investigador del Centro de Estudios Comparados de la Facultad de Humanidades y Ciencias de la UNL. Área de Investigación: Estudios Comparados, literaturas en lengua extranjera.
} 
La primera de ellas es un minucioso estudio de la historia literaria argentina y de los temas que la configuran. El viaje y el exilio (entendidos en todas sus variantes), el multilingüismo y el cosmopolitismo periférico, son las "claves de lectura" que permiten percibir la complejidad del constructo literario nacional. Pero es el primer tópico mencionado el que cobra una importancia central para Gasquet quien plantea "la incidencia del 'viaje' como núcleo problemático de primer orden en la conformación literaria e ideológica del proyecto de nación”. (2007: 23).

Concepto dilecto de los estudios comparados, el viaje obliga a la doble mirada: la de los europeos en Argentina y la de los argentinos en Europa, miradas complementarias que se hallan en nuestra historia literaria y en la génesis de la identidad nacional. En el capítulo "Viajeros del desierto", Gasquet analiza la doble influencia de la literatura de viajes escrita por los extranjeros que arribaban a nuestras tierras. El relato de la conformación geográfica y social de los territorios del sur moldeó la mirada europea de la zona del Río de la Plata, al mismo tiempo que construyó pautas paisajísticas y tópicos que retomaría nuestra incipiente literatura: la infinitud de la llanura pampeana, el desierto, el contraste de lo urbano y lo rural, el gaucho, la cautiva. Es así como en la mirada del otro, también los escritores de la época se encuentran y se definen. En "El viaje criollo" se estudia la otra cara de la moneda, la del viaje doble del criollo hacia el interior del territorio nacional y hacia el exterior. Según Gasquet, "la exploración interna del país, ese vasto movimiento por el que una élite se apropia de un territorio por medio del monopolio que ejerce su representación, se convierte pronto en un proyecto de dominación política”. (2007: 71) Aparece nuevamente la pampa, ahora como frontera entre la civilización y la barbarie. Pero no debemos entender el viaje de exploración interna y el viaje al extranjero como dos procesos disímiles, ambos se dan de manera simultánea y son viajes de búsqueda y de experimentación. El viaje al exterior, sobre todo a Europa, es el viaje de la búsqueda de modelos donde mirarse y de los que aprender a construir la identidad de la nación. El traspaso de los confines, el contrapunto del aquí y del allá, la toma de distancia y la puesta en perspectiva del país permiten descubrirlo, interpretarlo y poetizarlo configurando una literatura con personalidad propia.

Axel Gasquet cierra esta primera parte de su recorrido con los capítulos "Hacia una modernidad periférica" y el mencionado al inicio de nuestro comentario, "El puente cultural entre Buenos Aires y París", en los que analiza la relación particular de los escritores argentinos con la capital francesa desde mediados del siglo XIX hasta la generación actual residente en ella. En ambos apartados se muestra la irrenunciable presencia de Francia, y de la "ciudad luz" especialmente, como horizonte cultural de la clase ilustrada argentina, como resumen de la Europa ideal, a pesar de los períodos de transición en que ella, y el continente todo, eran reconocidos como lugares ya no seguros. Es la época de la primera guerra mundial y con el surgimiento de cierto campo cultural autónomo, la mirada nacional se vuelca paulatinamente a los Estados Unidos y surgen proyectos culturales, como la Revista Sur, con una impronta americanista que pone en crisis la hegemonía cultural europea. El crecimiento industrial de Buenos Aires, las oleadas inmigratorias a partir de 1870 y que producen la explosión demográfica de la ciudad en los primeros años del siglo XX, entre otros factores, llevan a la configuración de un nuevo espectro social, cultural y político. Los antiguos tópicos literarios se redefinen y el naciente criollismo y el posterior nacionalismo generan un debate 
de características propias. Pero París mantendrá su vigencia deslumbrando con las vanguardias artísticas allí surgidas.

A partir de 1930, los avatares políticos y sociales del país reintroducen, según Gasquet, las coordenadas del exilio (forzado o voluntario) para nuevas generaciones de intelectuales. Un éxodo masivo de los mismos hacia Europa se produce entre las décadas del 30 y del 50, y se repetirá con mayor fuerza en las décadas del 60 y del 70. El exilio es una tradición cultural argentina, por ello las nociones de "partida", "regreso" y "expatriación" cobran en ella una importancia fundamental.

La segunda parte de la investigación es la mejor invitación a la lectura del libro. El recorrido histórico, necesario y exhaustivo, desarrollado en la primera sección, se corona aquí con un lúcido análisis de las obras de seis escritores argentinos contemporáneos que eligen la ciudad de París como residencia. Mario Goloboff, Laura Futoransky, Arnaldo Calveyra, Juan José Saer (recordemos que este trabajo fue realizado antes de su muerte), Silvia Baron Supervielle y Héctor Bianciotti pertenecen a una misma generación y a partir de su producción literaria Axel Gasquet intenta determinar, recuperando los conceptos esgrimidos en la primera parte, "las distintas estrategias de poblamiento del imaginario social", es decir, la opción literaria que adopta cada escritor para poblar imaginariamente el vacío originario y existencial de la pampa. Cada uno de ellos recrea un "modo de ser con el mundo" por lo que dentro de cada universo particular, puede verse la forma en que elaboran un regreso narrativo a su tierra natal. Desde la distancia, las diversas estrategias de apropiación simbólica del pasado, llevan a cada escritor a recrear y actualizar los tópicos literarios argentinos en una misma línea de continuidad con la literatura precedente. Pero su aporte no queda allí sino que los enriquecen y les otorgan su sello personal. Estos seis escritores son muy distintos entre sí y el lazo más fuerte, el que los une insalvablemente, es inmaterial. Están ligados por "cierto imaginario literario común, un imaginario que en su pluralidad es al mismo tiempo netamente argentino". (Gasquet, 2007: 401).

Si exceptuamos la figura de Juan José Saer, y tal vez la de Héctor Bianciotti, los escritores contemporáneos argentinos estudiados en esta nueva publicación del centro editorial de la UNL no han sido objeto de investigaciones críticas. Tal vez se deba esto al largo exilio de alguno de ellos o a la marginalidad a la que se condena al escritor bilingüe en las literaturas nacionales. Recuperarlos, comenzar a poblar un espacio vacío, es el mayor mérito de Axel Gasquet quien, en su condición de argentino radicado en Francia, nos brinda una mirada dual que el comparatismo celebra. 